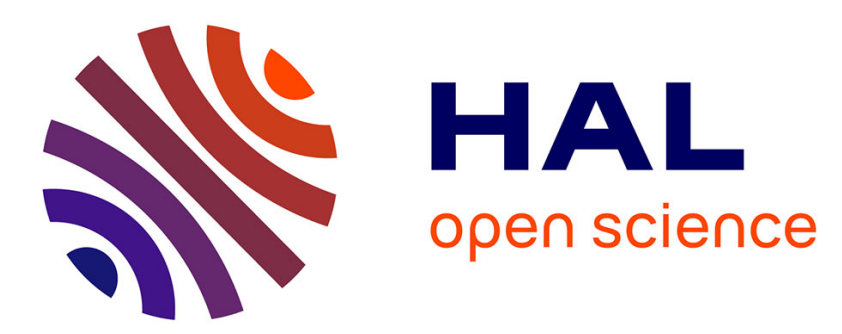

\title{
The role of Institutions in Transatlantic Employment Differences: A Life-Cycle View
}

\author{
Arnaud Chéron, Jean-Olivier Hairault, François Langot
}

\section{To cite this version:}

Arnaud Chéron, Jean-Olivier Hairault, François Langot. The role of Institutions in Transatlantic Employment Differences: A Life-Cycle View. Annals of Economics and Statistics, 2009, 95-96, pp.121138. hal-00623280

\author{
HAL Id: hal-00623280 \\ https://hal.science/hal-00623280
}

Submitted on 13 Sep 2011

HAL is a multi-disciplinary open access archive for the deposit and dissemination of scientific research documents, whether they are published or not. The documents may come from teaching and research institutions in France or abroad, or from public or private research centers.
L'archive ouverte pluridisciplinaire HAL, est destinée au dépôt et à la diffusion de documents scientifiques de niveau recherche, publiés ou non, émanant des établissements d'enseignement et de recherche français ou étrangers, des laboratoires publics ou privés. 


\title{
The Role of Institutions in Transatlantic Employment Differences: A Life-Cycle View
}

\author{
Arnaud Chéron* ${ }^{\dagger} \quad$ Jean-Olivier Hairault $\ddagger$ \\ François Langot $\S$
}

June 12, 2010

\begin{abstract}
Our objective in this paper is to show, by adopting a life-cycle unemployment equilibrium approach, that labor market institutions such as unemployment benefits, employment protection and mandatory retirement age have an age-differentiated impact which can explain agedifferentiated employment gaps between the US and French economies. Whereas the employment rates are quite similar for middle-aged workers, weaker rotations on the labor market lead to lower employment rates for younger workers. Moreover, the closer to 60 the retirement age, the lower the employment rate for workers aged between 50 and 59.
\end{abstract}

*University of Maine (GAINS) and EDHEC

${ }^{\dagger}$ Corresponding author: Arnaud Chéron, Faculté de Sciences Economiques, Université du Mans, Avenue olivier Messiaen, 72000 Le Mans. E-mail: acheron@univ-lemans.fr

${ }^{\ddagger}$ Paris School of Economics, University of Paris I and IZA

$\S$ PSE - Jourdan, CEPREMAP and University of Maine (GAINS) 


\section{Introduction}

National labor market performance is traditionally assessed by considering specific institutions such as employment protection (Blanchard and Portugal [2001]), unemployment insurance (Ljungqvist and Sargent [2004]) or tax systems and government (Prescott [2004], Rogerson [2006]). Until recently, all these studies have not recognized employment differences by age as central. This is quite surprising as policy makers are well aware that the employment differences across countries are centered at the extremity of the working life cycle. Recently, Prescott, Rogerson and Wallenius [2009] and Kitao, Ljungqvist and Sargent [2008] have acknowledged that any quantitative analysis of transatlantic differences in the labor market must seriously take this issue into account. Additionally, using a sample of 20 OECD countries, Bassanini and Duval (2006) show that the impact of the Social Security rules (implicit taxes on continued work, and the standard age of entitlement to old-age pension benefits) significantly decrease the employment rate of the 55-64 age group. They also note that these workers are more sensitive to the employment protection. Finally, concerning the employment rate of the 20-24 age group, their estimates suggest that young workers are more sensitive to unemployment benefits and employment protection than prime-age workers.

Our objective in this paper is to show, by adopting a life-cycle unemployment equilibrium approach, originally developed in Chéron, Hairault and Langot [2008a], that the labor market institutions have an age-differentiated impact which can explain age-differentiated employment gaps between countries. The starting point of our study relies on the following set of stylized facts, focusing more particularly on a transatlantic comparison between France and the US:

- Fact 1: The age-dynamic of employment is hump-shaped (Figure 1)

- Fact 2: The age-dynamic of labor market flows are characterized by (i) U-shaped inflow rates to unemployment (firing rates $^{1}$ ), and (ii) agedecreasing hiring rates (Figure 1).

\footnotetext{
${ }^{1}$ As is usual, we refer to firings even though we consider all the separations.
} 
Figure 1: France and US labor market statistics by age-group (1997-2003)
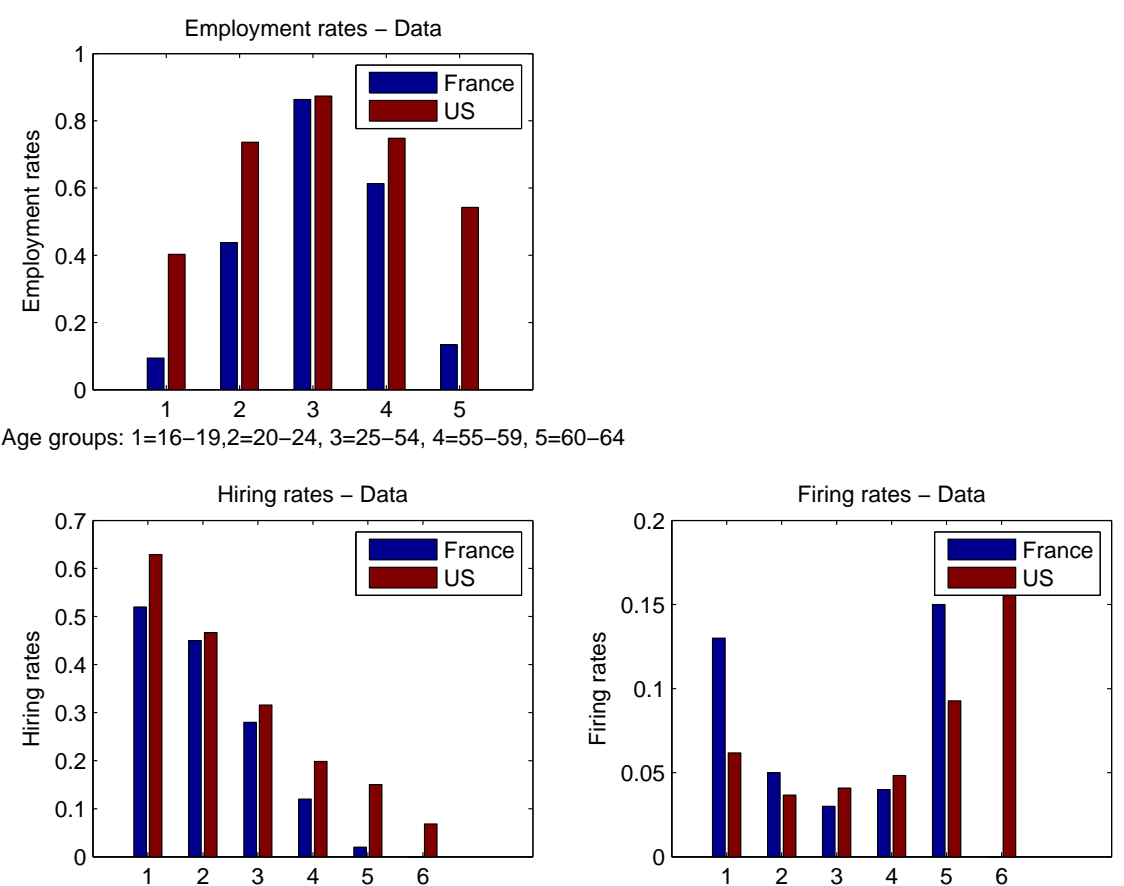

Age groups: $1=16-24 \cdot 2=25-34.3=35-49.4=50-54.5=55-59.6=60-64$

Figure 2: The gap in employment rates between France and the US from the 1970 s to 1990 s

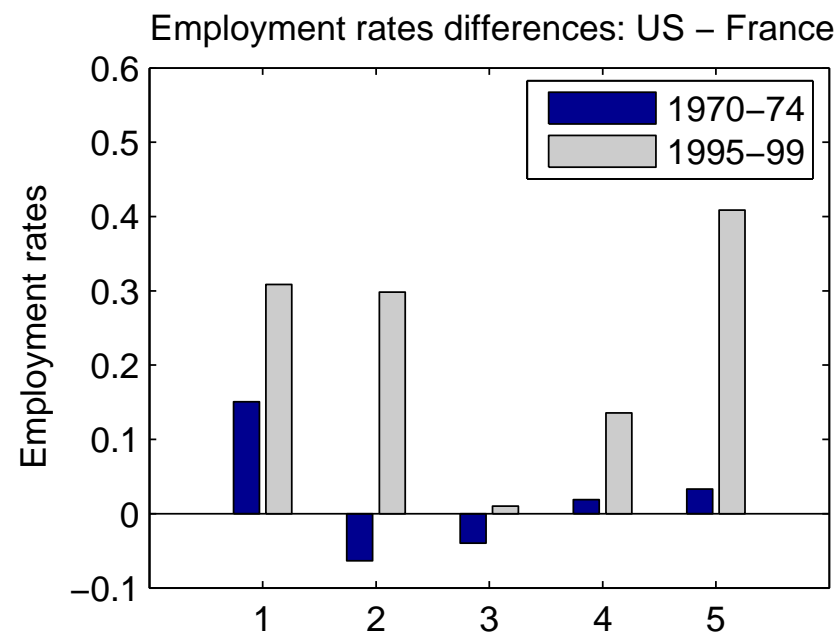

Age groups: $1=16-19,2=20-24,3=25-54,4=55-59,5=60-64$ 
- Fact 3: Whatever the decade, the employment rates of prime age workers are approximately the same in France as in the US. On the other hand, the gap for the younger (under 25) and the older (over 55) workers has risen considerably (see Figure 2).

In this paper, we investigate the age-differentiated effects on labor market flows, hence on employment rates, of labor market institutions such as unemployment benefits, employment protection and the mandatory retirement age. As we have observed changes in those institution in France, this could explain why the employment gap for the younger and the older workers with respect to the US has sharply increased.

Figure 3: Effective retirement ages and replacement ratios in France and the US
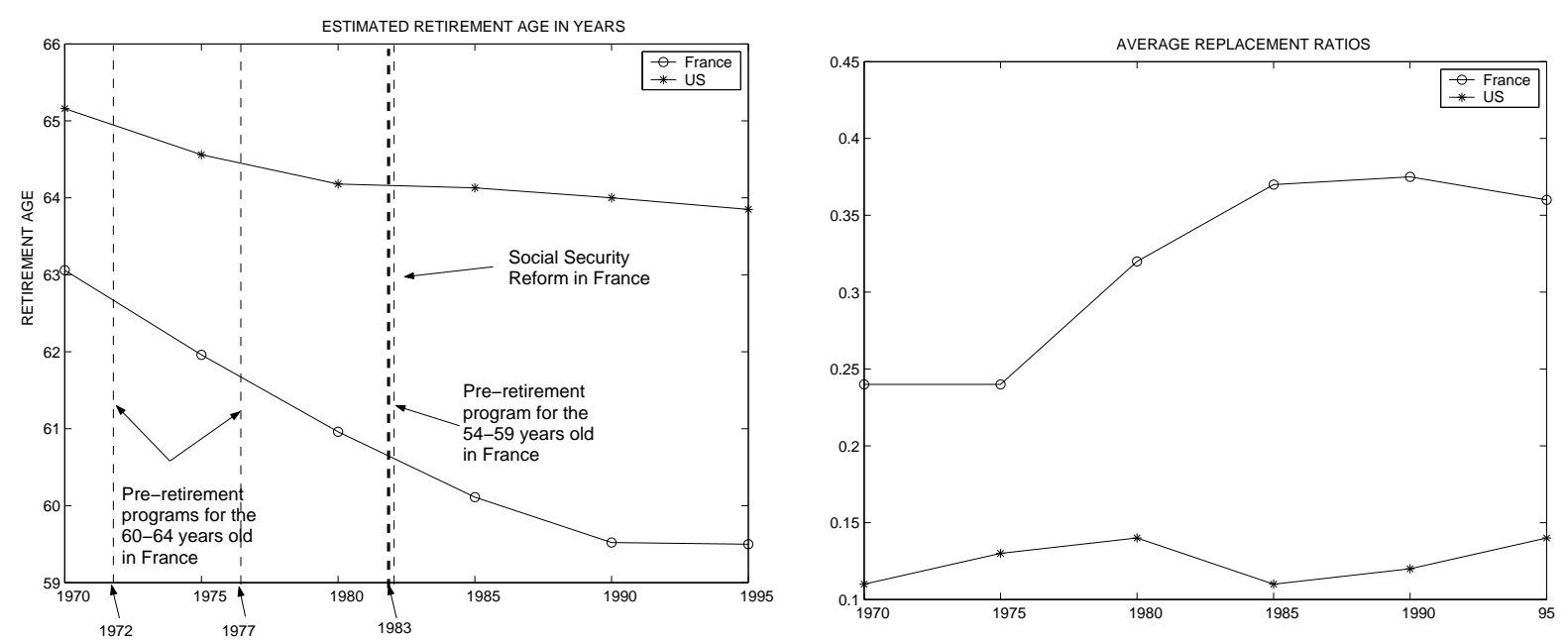

Figure 3, left panel, shows the changes in the effective retirement age (RA) in France and in the US: the gap has increased continuously to reach around five years in the mid-nineties. Similarly, the gap between the unemployment replacement ratios is twice as high at the end of the sample than at the beginning (Figure 3, right panel). Finally, France has also experimented with increasingly strict employment protection, whereas employment protection legislation (EPL) is quasi absent in the US. 
This paper primarily argues that these changes in institutions have a strong age-differentiated impact on firings and hirings, hence on life-cycle employment rates. So, we consider the job creation-job destruction approach to the labor market with a deterministic retirement age. This framework, which is an extension of Mortensen and Pissarides [1994] to a life-cycle approach, has been analyzed in Chéron, Hairault and Langot [2008a]. It implies that the firing (hiring) rate increases (decreases) with the age of the worker, because the time over which to recoup adjustment costs is decreasing when the worker gets closer to the retirement age. Otherwise stated, because the horizon of older workers is shorter, firms invest less in labor-hoarding activities at the end of the life cycle. This implies that the employment rate is falling at the end of the life-cycle, before the retirement age. Moreover, since it takes time to find a job, a lower employment rate for young workers arises from a queue phenomenon. The model we consider also takes into account exogenous specific human capital accumulation which raises the productivity of the job-worker pair. This increases the separation rate of younger workers who have on average a lower amount of specific human capital. The overall hump-shaped age-dynamic of employment rates is then well reproduced.

As a preliminary step, we provide some analytical results which allow us to emphasize the age-differentiated effects of the unemployment benefits, the firing tax and the retirement age. We then turn to the quantitative investigation, by first calibrating the model on the US economy over the period 1997-2003. We show that the model is able to match the observed age profile of both the employment rate and the hiring and the separation rates. We then propose a first counterfactual experiment which consists of considering the French institutions in this calibrated model: if the predictions of the model fitted the stylized facts about the French labor market, then differences in the unemployment replacement rate, the firing costs and the retirement age would be sufficient to explain the transatlantic gap in labor market performance. We show that the lower retirement age combined with high unemployment benefits in France account for all the employment gap of the 55-59 age-group. For the younger workers, the introduction of a "welfare state" explains a significant part of the lower rotations in France, and then of the lower employment rate for the 16-24 age-group, but it is not sufficient to 
account for the low level of the employment rate observed at the beginning of the 2000s in France. In a second counterfactual experiment, we show that the changes in these institutions that arose between 1970 and 2000 can account for much of the modification of the transatlantic employment gap.

Section 2 presents the theoretical framework. Its theoretical properties on the age-differentiated impact of the labor market institutions are analyzed in Section 3. The empirical assessment of the model is provided in Section 4. Section 5 concludes.

\section{Model}

We consider the life-cycle matching model developed in Chéron, Hairault and Langot [2008a]. Moreover, we assume the existence of a learning-by-doing process which improves the productivity of a specific match. An unemployment episode leads to a complete depreciation of this "specific" human capital. We also consider a version of this model with unemployment benefits and employment protection.

\subsection{Assumptions}

The model is in discrete time with $T$ the deterministic retirement date. At each period the older worker generation retiring from the labor market is replaced by a younger worker generation of the same size. The worker's age is perfectly known by employers. New workers start in the labor market as unemployed.

\subsubsection{Idiosyncratic productivity and human capital accumulation}

Firms are small and each has one job. The destruction flows derive from idiosyncratic productivity shocks that hit the jobs at random. Once a shock arrives, the firm has no choice but either to continue production or to destroy the job. Then, for age $i \in(2, T-1)$, employed workers are faced with layoffs when their job becomes unprofitable. At the beginning of each age, a job productivity $\epsilon$ is drawn in the general distribution $G(\epsilon)$ with $\epsilon \in[0, \bar{\epsilon}]$. The firms decide to close down any jobs whose productivity is below an (en- 
dogenous) productivity threshold (productivity reservation) denoted $R_{i}$. Job creation takes place when a firm and a worker meet. The flow of newly created jobs result from a matching function, the inputs of which are vacancies and unemployed workers. This flow also depends on productivity thresholds $R_{i}^{0}$ because it is assumed that productivity values $\epsilon$ are known after firm and worker have met.

The overall productivity of the job is $h_{j} \epsilon$ with $h_{j+1} \geq h_{j}$, where $j$ denotes the seniority. This human capital is job-specific: after an unemployment episode, the worker is at the minimal level of human capital, $h_{0}$.

\subsubsection{Worker flows with non age-directed search}

We assume that firms cannot ex-ante age-direct their search: there is a unique labor market tightness. The matching function, increasing in both its arguments and with constant returns-to-scale is defined by:

$$
M=M\left(v, \sum_{i} e_{i} u_{i}\right)
$$

Let $\theta=\frac{v}{\sum_{i} e_{i} u_{i}}$ denote the tightness of the labor market. It is then straightforward to define the probability for unemployed workers of age $i$ to be employed at age $i+1$, as $j c_{i} \equiv e_{i} p(\theta)\left[1-G\left(R_{i+1}^{0}\right)\right]$ with $p(\theta)=\frac{M(u, v)}{u}$. Similarly, we define the job destruction rate for an employed worker of age $i$ and seniority $j$ as $j d_{i}^{j}=G\left(R_{i}^{j}\right)$.

Let $n_{i}^{j}$ be the level of employment for workers of age $i$ and seniority $j$. $n_{i}=\sum_{j=0}^{i-1} n_{i}^{j}$ is the employment rate for workers of age $i$. The changes in employment according to workers' age can be stated as follows:

$$
\begin{aligned}
n_{i+1}^{j+1} & =n_{i}^{j}\left[1-G\left(R_{i+1}^{j+1}\right)\right] \forall j \geq 0, i \geq 1 \\
n_{i+1}^{0} & =u_{i} e_{i} p(\theta)\left[1-G\left(R_{i+1}^{0}\right)\right]
\end{aligned}
$$

In turn, the age-dynamic of unemployment solves:

$$
u_{i+1}=u_{i}\left(1-e_{i} p(\theta)\left[1-G\left(R_{i+1}^{0}\right)\right]\right)+\sum_{j=0}^{i-1} n_{i}^{j} G\left(R_{i+1}^{j+1}\right)
$$

for a given initial condition $u_{1}=1$. 


\subsection{Job value}

The expected values of a filled job by a worker of age $i$ are defined by:

$$
J_{i}^{j}(\epsilon)=h_{j} \epsilon-w_{i}^{j}(\epsilon)+\beta \int_{R_{i+1}^{j+1}}^{\bar{\epsilon}} J_{i+1}^{j+1}(x) d G(x)+\beta G\left(R_{i+1}^{j+1}\right)(V-F)
$$

with $w_{i}^{j}(\epsilon)$ the wage of a worker of age $i$ and tenure $j . F$ denotes a firing cost that refers to the costs implicit in mandated employment protection legislation.

\subsection{Hiring policy}

Any firm is free to open a job vacancy and engage in hiring. $c$ denotes the flow cost of recruiting a worker and $\beta \in[0,1]$ the discount factor. Let $V$ be the expected value of a vacant position, $q(\theta)$ the firm's probability of meeting a worker and $J_{i}^{0}(\epsilon)$ the initial value of a filled job with productivity $\epsilon$ :

$$
\begin{aligned}
V= & -c+\beta q(\theta) \sum_{i=1}^{T-1}\left[\frac{u_{i}}{u}\left(\int_{R_{i+1}^{0}}^{\bar{\epsilon}} J_{i+1}^{0}(x) d G(x)+G\left(R_{i+1}^{0}\right) V\right)\right] \\
& +\beta(1-q(\theta)) V
\end{aligned}
$$

Vacancies are determined according to the expected value of a contact with an unemployed worker. The expected value of a contact with an unemployed worker depends on the age distribution of the unemployed workers. Typically, the more older unemployed workers there are in the economy, the less is the expected return on a vacancy. This feature implies intergenerational externalities in the search process which leads to dismissing the Hosios condition as a first best requirement ${ }^{2}$.

The free-entry condition $(V=0)$ yields to:

$$
\underbrace{\frac{c}{q(\theta)}}_{\begin{array}{c}
\text { hiring } \\
\text { cost }
\end{array}}=\beta \sum_{i=1}^{T-1} \frac{u_{i}}{u} \underbrace{\int_{R_{i+1}^{0}}^{\bar{\epsilon}} J_{i+1}^{0}(x) d G(x)}_{\begin{array}{c}
\text { value of a job } \\
\text { for age } \mathrm{i}
\end{array}}
$$

\footnotetext{
${ }^{2}$ See Chéron, Hairault and Langot [2008a] for a more detailed discussion on the inefficiency of the decentralized equilibrium.
} 


\subsection{Firing policy}

The firm's optimal choice is to not create (destroy) a job when its value falls below zero (the firing cost), that is:

$$
J_{i}^{0}(\epsilon)<0 \quad J_{i}^{j}(\epsilon)<-F
$$

This leads to reservation productivity levels $R_{i}^{0}$ and $R_{i}^{j}$ that solve:

$$
J_{i}^{0}\left(R_{i}^{0}\right)=0 \text { and } J_{i}^{j}\left(R_{i}^{j}\right)=-F \quad \forall i, j \geq 1
$$

$R_{i}^{0}$ determines the set of new jobs, whereas $R_{i}^{j}$ gives the set of fired workers of age $i$ with the tenure $j$. The productivity threshold $R_{i}^{j}$ is given by:

$$
h_{j} R_{i}^{j}=\underbrace{w_{i}^{j}\left(R_{i}\right)}_{\begin{array}{c}
\text { labor } \\
\text { cost }
\end{array}}-\underbrace{F}_{\begin{array}{c}
\text { current } \\
\text { firing } \\
\text { cost }
\end{array}}+\underbrace{\beta G\left(R_{i+1}^{j+1}\right) F}_{\begin{array}{c}
\text { expected } \\
\text { firing cost }
\end{array}}-\underbrace{\beta \int_{R_{i+1}^{j+1}}^{\bar{\epsilon}} J_{i+1}^{j+1}(x) d G(x)}_{\begin{array}{c}
\text { expected } \\
\text { surplus }
\end{array}}
$$

The higher the wage, the higher the reservation productivity, and hence the higher the job destruction flows. On the other hand, the higher the option value of filled jobs (the expected surplus in the future), the weaker the job destructions. Because the job value vanishes at the end of the working life, labor hoarding of older workers is less profitable. On the other hand, the firing costs are particularly efficient for the employment of older workers ${ }^{3}$. Older workers also benefit from their higher level of human capital on average. These last two effects can offset the horizon effect.

The productivity threshold for the hirings is given by:

$$
h_{0} R_{i}^{0}=\underbrace{w_{i}^{0}\left(R_{i}^{0}\right)}_{\begin{array}{c}
\text { labor } \\
\text { cost }
\end{array}}+\underbrace{\beta G\left(R_{i+1}^{1}\right) F}_{\begin{array}{c}
\text { expected } \\
\text { firing cost }
\end{array}}-\underbrace{\beta \int_{R_{i+1}^{1}}^{\bar{\epsilon}} J_{i+1}^{1}(x) d G(x)}_{\begin{array}{c}
\text { expected } \\
\text { surplus }
\end{array}}
$$

Job creations decrease with age as the expected surplus is reduced by the proximity to retirement. Regarding hirings, there is no protection for human capital or from firing costs.

\footnotetext{
${ }^{3}$ This point is more particularly analyzed in Chéron, Hairault and Langot [2008b].
} 


\subsection{Search effort}

Making the search effort endogenous reinforces the decrease in the employment rate at the end of working life, as is shown in Ljungqvist ad Sargent [2008] and Hairault, Langot and Sopraseuth [2010]. As the retirement age gets closer, the return on job-search investments decreases because the horizon (the expected job duration) over which workers can recoup their investment is reduced. The endogenous search effort is derived from the following intertemporal problem:

$$
\begin{aligned}
\mathcal{U}_{i}= & \max _{e_{i}}\left\{b+z-\phi\left(e_{i}\right)+\beta\left[\left(1-e_{i} p(\theta)\right) \mathcal{U}_{i+1}\right.\right. \\
& \left.\left.+e_{i} p(\theta)\left(\int_{R_{i+1}^{0}}^{\bar{\epsilon}} \mathcal{W}_{i+1}^{0}(x) d G(x)+G\left(R_{i+1}^{0}\right) \mathcal{U}_{i+1}\right)\right]\right\}
\end{aligned}
$$

The optimal search intensity satisfies

$$
\phi^{\prime}\left(e_{i}\right)=\beta p(\theta) \int_{R_{i+1}^{0}}^{\bar{\epsilon}}\left[\mathcal{W}_{i+1}^{0}-\mathcal{U}_{i+1}\right](x) d G(x)
$$

For a given $R_{i+1}^{0}, e_{i}$ decreases with age as $\mathcal{W}_{i+1}^{0}-\mathcal{U}_{i+1}$ decreases with age according to the worker's horizon effect. For a given $\mathcal{W}_{i+1}^{0}-\mathcal{U}_{i+1}, e_{i}$ decreases because $R_{i+1}^{0}$ increases according to the firm's horizon effect.

\subsection{Wage bargaining}

The rent associated with a job is divided between the employer and the worker according to a wage rule. Following the most common specification, wages are determined by the Nash solution to a bargaining problem ${ }^{4}$. The bargaining power of the workers is considered as constant across ages. The global surplus generated by a job is divided according to a sharing rule according to a two-tier wage structure. We have the two following sharing rules which determine the wage $w_{i}^{0}(\epsilon)$ of the newly hired workers and the wage $w_{i}^{j}(\epsilon)$ of the workers of tenure $j$ respectively:

$$
\begin{aligned}
& \mathcal{W}_{i}^{0}(\epsilon)-\mathcal{U}_{i}=\gamma\left[J_{i}^{0}(\epsilon)+\mathcal{W}_{i}(\epsilon)-\mathcal{U}_{i}\right] \\
& \mathcal{W}_{i}^{j}(\epsilon)-\mathcal{U}_{i}=\gamma\left[J_{i}^{j}(\epsilon)-(V-F)+\mathcal{W}_{i}^{j}(\epsilon)-\mathcal{U}_{i}\right]
\end{aligned}
$$

\footnotetext{
${ }^{4}$ This wage setting rule has been somewhat disputed (See for instance Shimer [2005]. We leave the exploration of alternative wage rules to future research.
} 
Equations for the initial and subsequent wages are given by:

$$
\begin{aligned}
w_{i}^{0}(\epsilon)= & (1-\gamma)\left(b+z-\phi\left(e_{i}\right)\right) \\
& +\gamma\left(h_{0} \epsilon+\beta e_{i} p(\theta) \int_{R_{i+1}^{0}}^{\bar{\epsilon}} J_{i+1}^{0}(x) d G(x)-\beta F\right) \\
w_{i}^{j}(\epsilon)= & (1-\gamma)\left(b+z-\phi\left(e_{i}\right)\right) \\
& +\gamma\left(h_{j} \epsilon+\beta e_{i} p(\theta) \int_{R_{i+1}^{0}}^{\bar{\epsilon}} J_{i+1}^{j}(x) d G(x)+(1-\beta) F\right)
\end{aligned}
$$

Let $\tau_{i}$ denote the relative job value of age $i$ to the average job value:

$$
\tau_{i} \equiv \frac{\int_{R_{i+1}^{0}}^{\bar{\epsilon}} J_{i+1}^{0}(x) d x}{\sum_{i=1}^{T-1}\left(\frac{u_{i}}{u} \int_{R_{i+1}^{0}}^{\bar{\epsilon}} J_{i+1}^{0}(x) d x\right)} \text { with }\left\{\begin{array}{l}
\tau_{1}>1 \\
\tau_{T-1}<1
\end{array}\right.
$$

The wage equations can be rewritten as follows:

$$
\begin{aligned}
& w_{i}^{0}(\epsilon)=(1-\gamma)\left(b+z-\phi\left(e_{i}\right)\right)+\gamma\left(h_{0} \epsilon+c \theta \tau_{i}-\beta F\right) \\
& w_{i}^{j}(\epsilon)=(1-\gamma)\left(b+z-\phi\left(e_{i}\right)\right)+\gamma\left(h_{j} \epsilon+c \theta \tau_{i}+(1-\beta) F\right)
\end{aligned}
$$

It is worth emphasizing that the way market tightness enters the wage equation in our model depends on the worker's age through the variable $\tau_{i}$. This variable gives the value of a worker hired at age $i$ relative to the expected value of a job according to the age distribution of unemployed workers ${ }^{5} . \tau_{i}$ decreases with age. This implies that the bargaining strength of a young worker is greater than that of an old worker, and, consequently, for a given productivity level $\epsilon$, that the wage is lower for a worker of age $i+1$ than for a worker of age $i, w_{i+1}(\epsilon) \leq w_{i}(\epsilon)$. Ultimately, we have $w_{T-1}(\epsilon)=\gamma \epsilon+(1-\gamma) b$.

\footnotetext{
${ }^{5}$ So that we typically have $\tau_{1}>1$ for the youngest workers and $\tau_{T-1}<1$ for the oldest ones, or more generally $\tau_{i+1} \leq \tau_{i}$.
} 


\subsection{Equilibrium}

A labor market equilibrium with wage bargaining exists and it is characterized by ${ }^{6}$ :

$$
\begin{aligned}
\frac{c}{q(\theta)}= & \beta(1-\gamma) \sum_{i}\left[\frac{u_{i}}{u}\left(h_{0} \int_{R_{i+1}^{0}}^{\bar{\epsilon}}[1-G(x)] d x\right)\right] \\
R_{i}^{0}= & b+z-\phi\left(e_{i}\right)+\beta F-\beta h_{1} \int_{R_{i+1}^{1}}^{\bar{\epsilon}}[1-G(x)] d x \\
& +\gamma \beta e_{i} p(\theta) h_{0} \int_{R_{i+1}^{0}}^{\bar{\epsilon}}[1-G(x)] d x \\
h_{j} R_{i}^{j}= & b+z-\phi\left(e_{i}\right)-(1-\beta) F-\beta h_{j+1} \int_{R_{i+1}^{j+1}}^{\bar{\epsilon}}[1-G(x)] d x \\
& +\gamma \beta e_{i} p(\theta) h_{0} \int_{R_{i+1}^{0}}^{\bar{\epsilon}}[1-G(x)] d x \\
\phi^{\prime}\left(e_{i}\right)= & \gamma \beta p(\theta) h_{0} \int_{R_{i+1}^{0}}^{\bar{\epsilon}}[1-G(x)] d x \\
n_{i+1}^{j+1}= & n_{i}^{j}\left[1-G\left(R_{i+1}^{j+1}\right)\right] \forall j \geq 0, i \geq 1 \\
n_{i+1}^{0}= & u_{i} e_{i} p(\theta)\left[1-G\left(R_{i+1}^{0}\right)\right] \\
u_{i+1}= & u_{i}\left(1-p(\theta)\left[1-G\left(R_{i+1}^{0}\right)\right]\right)+\sum_{j=0}^{i-1} n_{i}^{j} G\left(R_{i+1}^{j+1}\right)
\end{aligned}
$$

with terminal conditions $h_{T-1}^{j} R_{T-1}^{j}=b-F, R_{T-1}^{0}=b$, and a given initial condition $u_{1}$.

\section{Theoretical properties}

We now address the issue of the relationship between labor market institutions and the age-dynamics of employment. For simplicity, the results are derived without human capital accumulation, that is $h_{j}=h_{j+1}=1, \forall j$. We investigate the properties of two different economies:

- The first economy is characterized by no employment protection $(F=$ ${ }^{6}$ Note that $J_{i}^{j}=(1-\gamma) h_{j} \int_{R_{i+1}^{j}}^{\bar{\epsilon}}[1-G(x)] d x$. 
0 ), low unemployment benefits denoted $\underline{b}$, and a high retirement age $\bar{T}$. This economy is called a laissez-faire economy.

- The second economy is characterized by the existence of employment protection and high unemployment benefits such that $F>0$ and $\bar{b}>\underline{b}$, and a shorter retirement age $\underline{T}<\bar{T}$. This shorter retirement age can be interpreted as a higher tax on continued activity. This economy is called a welfare-state economy.

Our goal is then to show how these different institutions can be consistent with identical employment rates for middle-aged workers, but lower employment rates for the young worker and for the seniors in the second economy than in the first economy.

\subsection{The impact of labor market institutions on the em- ployment of younger workers}

In order to focus only on the dynamic of younger worker employment, let us assume that the first cohort of the economy has an infinite lifetime $(T \rightarrow \infty)$. In this case, $R_{i}$ jumps instantaneously to its stationary value $R^{\star}$. Indeed, as the dynamic of $R_{i}$ is stable backward, $R_{i}=R^{\star}$ is the unique value of $R_{i}$ on the saddle path (see Figure 4). Let us consider the following equations at the steady state:

$$
\begin{aligned}
R^{\star}= & b+z-\phi\left(e^{\star}\right)-(1-\beta) F-\beta \int_{R^{\star}}^{\bar{\epsilon}}[1-G(x)] d x \\
& +\gamma \beta e^{\star} p(\theta) \int_{R^{0}}^{\bar{\epsilon}}[1-G(x)] d x \\
R^{0}= & R^{\star}+F \\
\phi^{\prime}\left(e^{\star}\right)= & \gamma \beta p(\theta) \int_{R^{0}}^{\bar{\epsilon}}[1-G(x)] d x
\end{aligned}
$$

These equations allow us to find the reservation productivity as a function of the labor market policies: $R^{\star}=\mathcal{R}(b, F)$. We then deduce the job creation and the job destruction rates $\operatorname{JCrate}(b, F)$ and $J$ Drate $(b, F)$. Hence, when $T \rightarrow \infty$, the age-dynamic employment can be reduced to the following 
Figure 4: Equilibrium dynamics of $\left\{R_{i}, n_{i}\right\}$

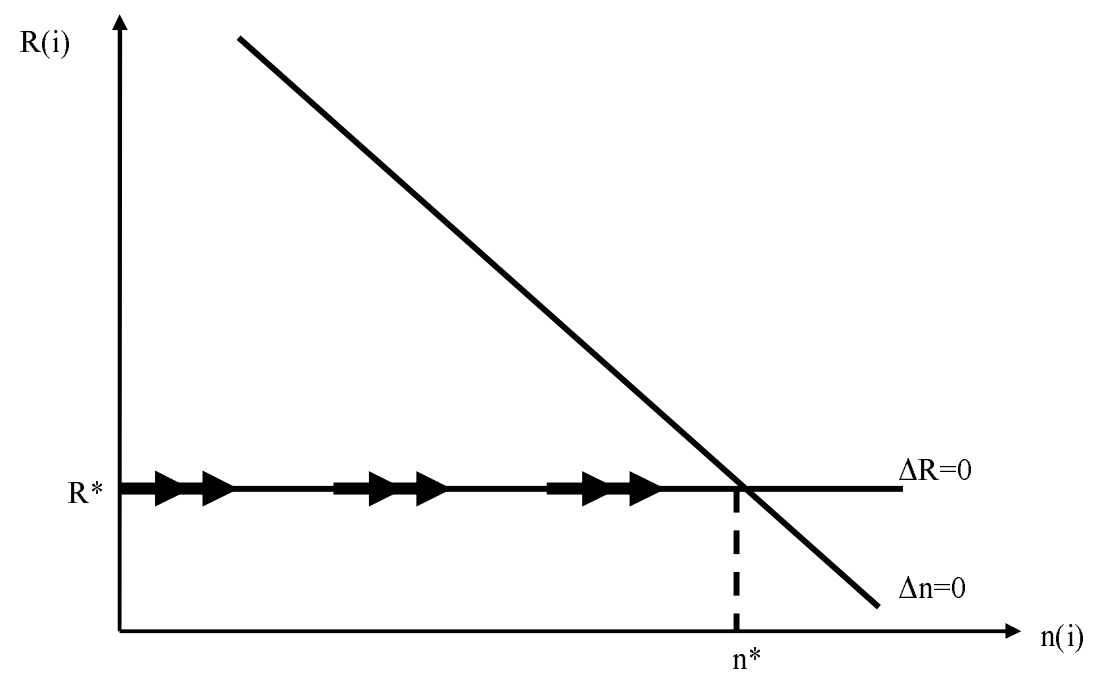

equation:

$$
\begin{aligned}
n_{i}= & {[1-\operatorname{JCrate}(b, F)-J \operatorname{Drate}(b, F)] n_{i-1}+\operatorname{JCrate}(b, F) } \\
& \text { with }\left\{\begin{array}{l}
\operatorname{JCrate}(b, F)=e^{\star} p(\theta)\left[1-G\left(R^{\star}+F\right)\right] \\
\operatorname{JDrate}(b, F)=G\left(R^{\star}\right)
\end{array}\right.
\end{aligned}
$$

given the initial condition $n_{1}$. This equation describes the transitional path of younger worker employment until convergence to an age-stationary level, denoted by $n^{\star}$.

It is then possible to show how differences in labor market institutions can be consistent with identical age-stationary employment rates, but lower employment rates for the younger workers in the welfare-state economy. Starting with the initial condition $n_{1}$, the transitional age-dynamics of employment are characterized by the speed of adjustment to reach the age-stationary employment rate. Since the labor market tightness and the reservation productivity are not age-dependent when $T \rightarrow \infty$, we thus have a constant speed 
of adjustment from $n_{1}$ to $n^{\star}$. This speed of adjustment is defined by:

$\left|\frac{\partial \Delta n_{i}}{\partial n_{i-1}}\right|=\left\{\begin{array}{ccc}\operatorname{JCrate}(\bar{b}, F)+\operatorname{JDrate}(\bar{b}, F) & \equiv \mu(\bar{b}, F) & \Longleftrightarrow \text { welfare state } \\ \operatorname{JCrate}(\underline{b}, 0)+\operatorname{JDrate}(\underline{b}, 0) & \equiv \mu(\underline{b}, 0) & \Longleftrightarrow \text { laissez-faire }\end{array}\right.$

For a given level of $\underline{b}$, there exist $\bar{b}$ and $F$ such that $J \operatorname{Drate}(\underline{b}, 0)=x \times$ $\operatorname{JDrate}(\bar{b}, F)$ and $\operatorname{JCrate}(\underline{b}, 0)=x \times \operatorname{JCrate}(\bar{b}, F)$ with $x>1$. These particular values for $\bar{b}$ and $F$ may imply the same age-stationary employment rate, $n^{\star}$, in the two economies. However, it is obvious that the age-dynamics of employment to reach $n^{\star}$ take more time in the welfare state economy than in the laissez-faire: $\mu(\underline{b}, 0)=x \times \mu(\bar{b}, F)>\mu(\bar{b}, F)$. Lower job flows contribute to increasing the younger workers' employment rate.

Clearly, starting with the same initial condition $n_{1}=0$, an economy with higher rotations leads to a faster increase in employment: the employment rate of younger workers converges more quickly toward the age-stationary employment rate.

For $T$ finite but high enough, the results are qualitatively the same. Although $R_{i}$ does not jump to its age-stationary value, we have the fact that $R_{i} \rightarrow R^{\star}$, at the beginning of the life cycle for $T$ sufficiently large. Then, the age-dynamics of employment are approximately the same for younger workers as obtained when $T \rightarrow \infty$. This reflects the fact that the terminal condition only has a significant impact on the age-dynamics of older worker employment.

\subsection{The impact of the finite life-time assumption on the older workers}

Turning to the issue of older worker employment, the key parameter of the model is the retirement age. The age profile of hirings and firings has been recursively determined from terminal conditions. On the other hand, the age profile of unemployment $u_{i}$ (or employment $n_{i}=1-u_{i}$ ) depends on the arbitrary initial condition $u_{1}$. Then we have:

$$
\begin{aligned}
u_{i+1} & =u_{i}\left[1-e_{i} p(\theta)\left(1-G\left(R_{i+1}\right)\right)\right]+G\left(R_{i+1}\right)\left(1-u_{i}\right) \\
\Leftrightarrow u_{i+1}-u_{i} & =G\left(R_{i+1}\right)-u_{i}\left[e_{i} p(\theta)\left(1-G\left(R_{i+1}\right)\right)+G\left(R_{i+1}\right)\right]
\end{aligned}
$$


implying that

$$
u_{i} \gtrless \frac{G\left(R_{i+1}\right)}{G\left(R_{i+1}\right)+e_{i} p(\theta)\left(1-G\left(R_{i+1}\right)\right)} \Rightarrow n_{i+1} \gtrless n_{i} \quad \forall i
$$

For $u_{1}=1$, Chéron, Hairault and Langot [2008a] show that there exists a

Figure 5: Equilibrium dynamics of $\left\{R_{i}, n_{i}\right\}$

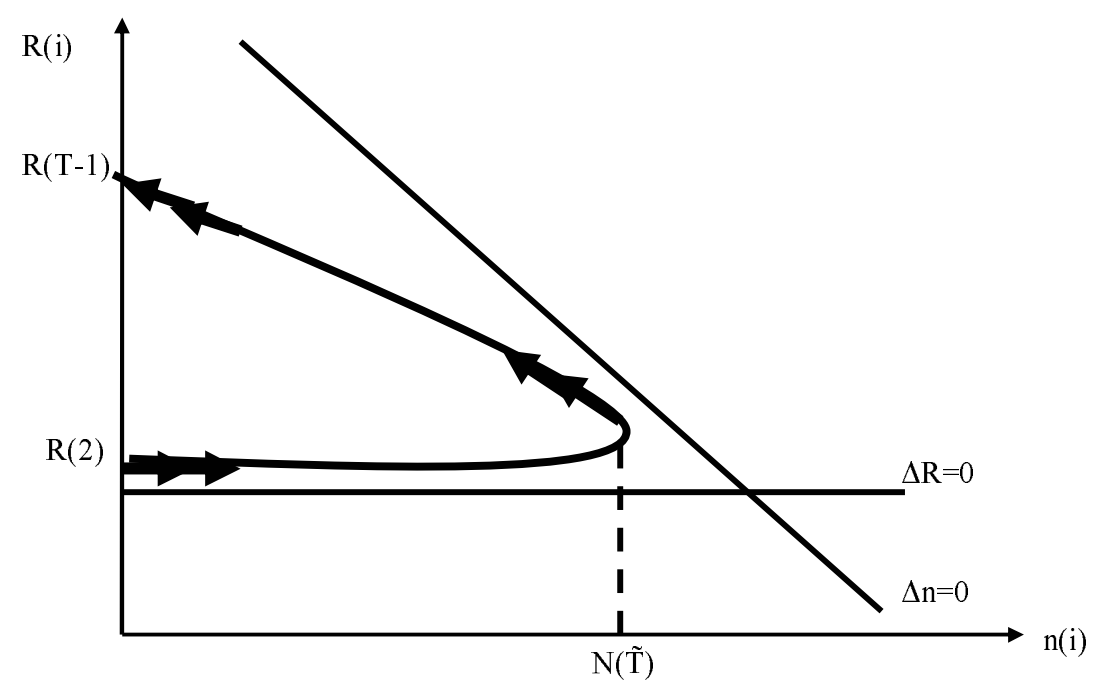

threshold age $\tilde{T}$ such that $n_{i} \geq n_{i-1} \quad \forall i \leq \tilde{T}$ and $n_{i} \leq n_{i-1} \quad \forall i \geq \tilde{T}$ (see Figure 5). Until the age $\tilde{T}$, the increase in the employment rate is the result of a queue phenomenon: at the age of entry on the labor market, there are only few firings, whereas hirings are greater. From $\tilde{T}$ onwards, the hiring rate declines whereas the destruction rate increases, leading to lower employment rates for older workers.

The definition of the equilibrium emphasizes that we have the same terminal condition whatever the value of $T$ : for two retirement ages, namely $\underline{T}=T$ and $\bar{T}=T+N$, we have $R_{T-1}=R_{T+N-1}=b-F$. Then, from backward induction, $R_{T-1-i}=R_{T+N-1-i} \forall i$. It appears that age in itself does not matter for these equilibrium dynamics. Only the distance to this retirement age is of interest. This suggests that the predicted decrease (increase) 
with age in the job finding rate (reservation productivity) occurs sooner in economies where the retirement age is lower.

\section{Empirical assessment}

In this section, we consider the US economy which is certainly the closest one to our streamlined laissez-faire economy, whereas France can be considered as representative of the welfare-state economy. We consider the flows onto the labor market for different ages. We then compute the annual hiring rate of non employed workers and the annual separation rate of employed workers for different categories of age from the CPS and from the "Enquete Emploi" over the period 1997-2003. We consider only men. We observe that the destruction rates are U-shaped and the creation rates are decreasing with age, both in the US and in the French data (see Figure 1 in the introduction). Is the model able to replicate such flows as an implication of country-specific labor market institutions, such as unemployment benefits, employment protection and the retirement age? Do observed changes in these labor market institutions explain the change in the employment gap between France and the US? This section seeks to give some quantitative answers to these questions.

\subsection{Calibration}

We propose to clarify the calibration strategy by distinguishing parameters calibrated on external information and parameters calibrated in order to make the model consistent with empirical counterparts. We calibrate our model on US data. In order to use the employment rates by age as overidentifying restrictions, our strategy is to use as much external information as possible, such as for the bargaining power, the elasticity of the matching function and the discount factor: $\gamma=\psi=0.5$ and $\beta=0.96$ (Mortensen and Pissarides [1999]).

The other parameters are calibrated in order to match observed targets:

- The dynamic of the human capital accumulation is assumed to be governed by the process: $h_{j}=\alpha_{0}+\alpha_{1} \times j+\alpha_{1} \times j^{2}$. The human capital 
accumulation is calibrated in order to match the return on 10 years of tenure (see Altonji and Williams [2005])

- The recruiting cost $c$ is set in order to match the estimates of Abowd and Kramarz (2003).

- In the 2000s, the US institutions are calibrated in the following way:

- Unemployment benefits $z$ are chosen in order to match the observed average replacement rate 0.12 .

- The firing costs $F$ are equal to 0 .

- This retirement age is set at 64 .

We assume that the home production is specific to each country $\left\{b_{U S}, b_{F R}\right\}$. Then, given that the disutility of the search effort has the following functional form, $\phi\left(e_{i}\right)=\chi\left(\frac{e_{i}^{1+\nu}}{1+\nu}\right)$, it remains to calibrate the 4 parameters, $\{\chi, \nu\}$ and $\left\{b_{U S}, b_{F R}\right\}$. As our analysis is focused on the implications of our model at the beginning and at the end of the life cycle, they are calibrated in order to match the employment rate and the separation rate of the middle-aged workers in the US and in France at the beginning of the 2000s.

\subsection{A first assessment on the US economy}

Considering the US economy, our calibration strategy implies that the model matches the employment and the separation rate of the workers aged 3049. The key issue about the empirical relevance of our model then relies on its ability to account for job creation and job destruction flows for both younger and older workers. Simulation results are plotted in Figure 6. Firstly, they show that our model is able to account both for lower younger and older employment rates in the US. Secondly, Figure 6 shows that our model matches quite well the age-pattern of separation and hiring rates over the life cycle. The introduction of human capital accumulation allows us to reproduce the U-shaped age-dynamic in the separation rate: at the beginning of the life-cycle, the average level of human capital of the employed workers is low, implying that the jobs are sensitive to idiosyncratic shocks. Because experience increases with the age of the worker, the worker productivity 
Figure 6: Model Assessment: US - 2000

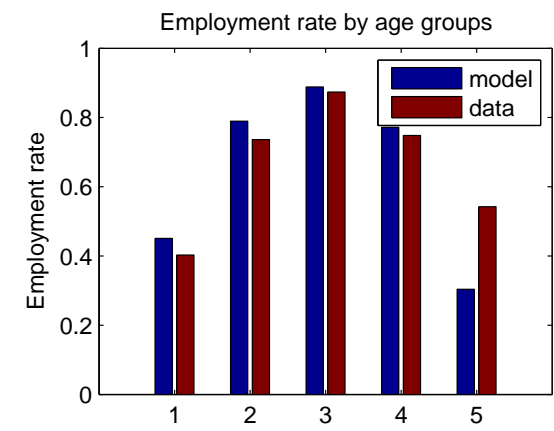

Age groups: $1=16-19,2=20-24,3=25-54,4=55-59,5=60-64$
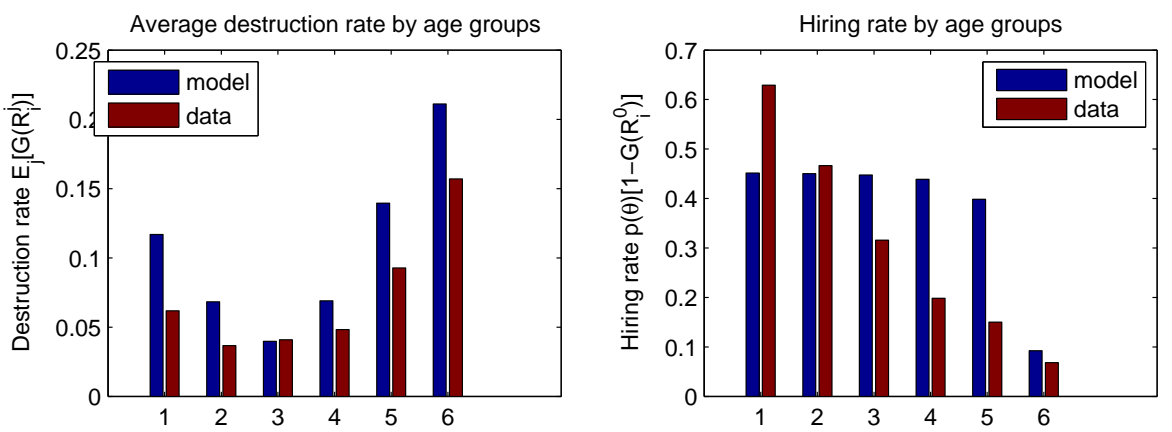

increases with age, leading jobs to be more immune to productivity shocks when occupied by middle-aged workers. But, at the end of the life-cycle, this higher productivity is overcompensated by the "horizon effect": the older workers are more sensitive to idiosyncratic shocks because labor hoarding is less profitable just before retirement.

However, it must be acknowledged that the flow levels are not perfectly reproduced. More particularly, the hiring rates of the age group 50-59 are overestimated by the model. The job finding rate of this population decreases more in the data than in the model. The model is more relevant to capturing the more pronounced decline in the hiring rate when the retirement age is imminent (between 60 and 64).

Overall, we consider that this simple model works quite well to generate the age profile of hirings and separations over the life cycle. The sensitivity of hiring and separation rates to the retirement horizon is quantitatively significant. 


\subsection{A first counterfactual experiment: the actual French institutions}

We simulate the same model calibrated using the same parameters as before, except that we consider the French labor market institutions ${ }^{7}$ at the beginning of the 2000s:

- The unemployment replacement rate $z$ is set to 0.35 (Figure 3).

- $F$ is set according to the estimates of Garibaldi and Violante (2002): the layoff tax would represent one third of the average annual earnings.

- The retirement age is set at 60 .

The results of this counterfactual experiment are presented in Figure 7. On

Figure 7: Model Assessment: France - 2000

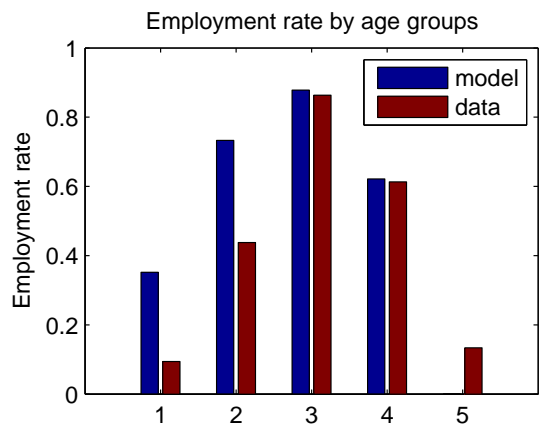

Age groups: $1=16-19,2=20-24,3=25-54,4=55-59,5=60-64$
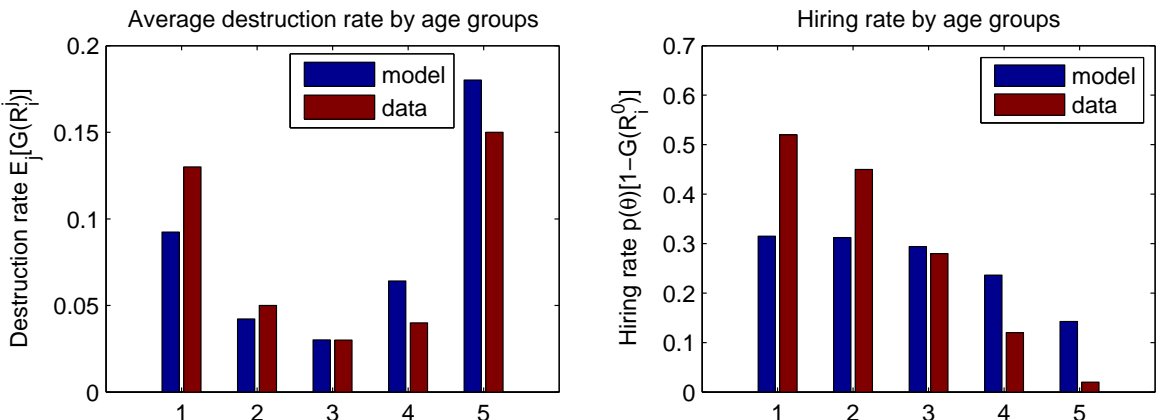

Age groups: $1=16-24,2=25-34,3=35-49,4=50-54,5=55-59$

the one hand, high EPL and UB introduce some delays in the increase of

\footnotetext{
${ }^{7}$ Note that that we have also introduced heterogeneity in the home production parameter $b$ in order to match the employment and the job separation rate for the $35-49$ age-group.
} 
younger worker employment: the employment rate predicted by the model for the young workers in France is lower than in the US. This result is explained by lower job flows for the 16-24 age-group in France than in the US: whereas the hiring and firing rates are equal to $40 \%$ and $12 \%$ respectively in the US, they fall to $30 \%$ and $9 \%$ in France. The lower rotation rate in France implies that the employment rate of younger workers converges more slowly toward the age-stationary employment rate. Quantitatively, this represents approximatively an employment loss equal to 7 percentage points for the 1619 age-group and to 5 percentage points for the 20-25 age-group. On the other hand, despite employment protection, the lower retirement age combined with a high replacement rate in France leads firms to decrease hirings and increase firings from 50 years old onward, whereas it only occurs from 55 in the US. These results show that differences in both labor market institutions and retirement ages can account for large employment rate differences at the beginning and at the end of the life cycle (Figure 8). However, it must be acknowledged that the differences observed for the younger workers are worse in the data than in the model. Kitao, Ljungqvist and Sargent [2009] have recently emphasized the negative role played in France by the minimum wage regulation, especially for the younger workers. This is clearly a shortcoming in our streamlined framework of not considering this labor market dimension.

Figure 8: Employment rates in France and the USA - 2000

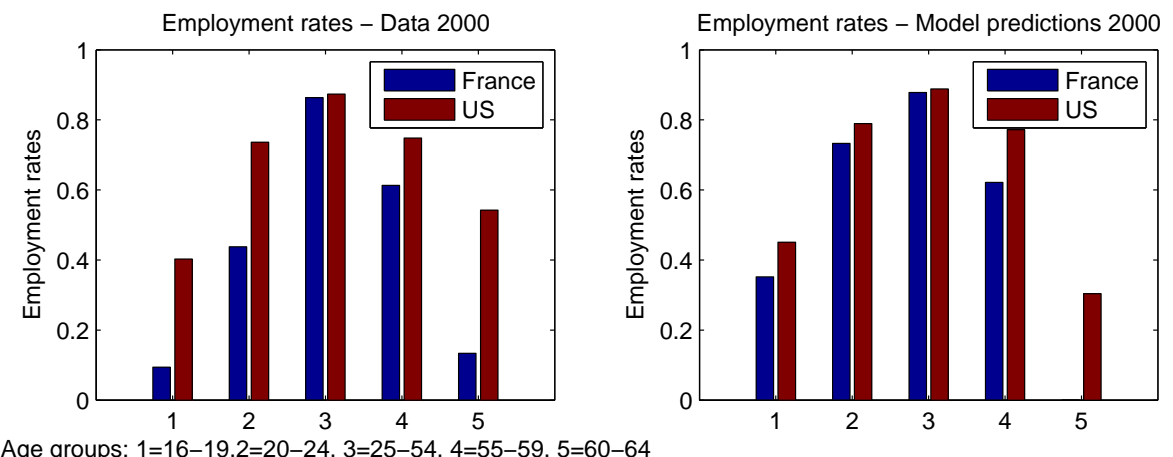




\subsection{The French institutions in $\mathbf{1 9 7 0}$}

Empirical evidence presented in Bassanini and Duval (2006) supports the idea that a sizable share of the cross-country unemployment changes between 1982 and 2003 can be explained by changes in the labor market and SS institutions. In this section, we provide empirical support for this view. We consider the French institutions in the 1970s, mostly keeping the US institutions unchanged ${ }^{8}$.

- The retirement age is set at 63 in France and 65 in the US in 1970.

- In France, the average replacement rate is set at 0.25 and $F$ is divided by 3 in 1970. The LMI in the US are considered unchanged.

Figure 9: Employment rates in France and the USA - 2000/1970
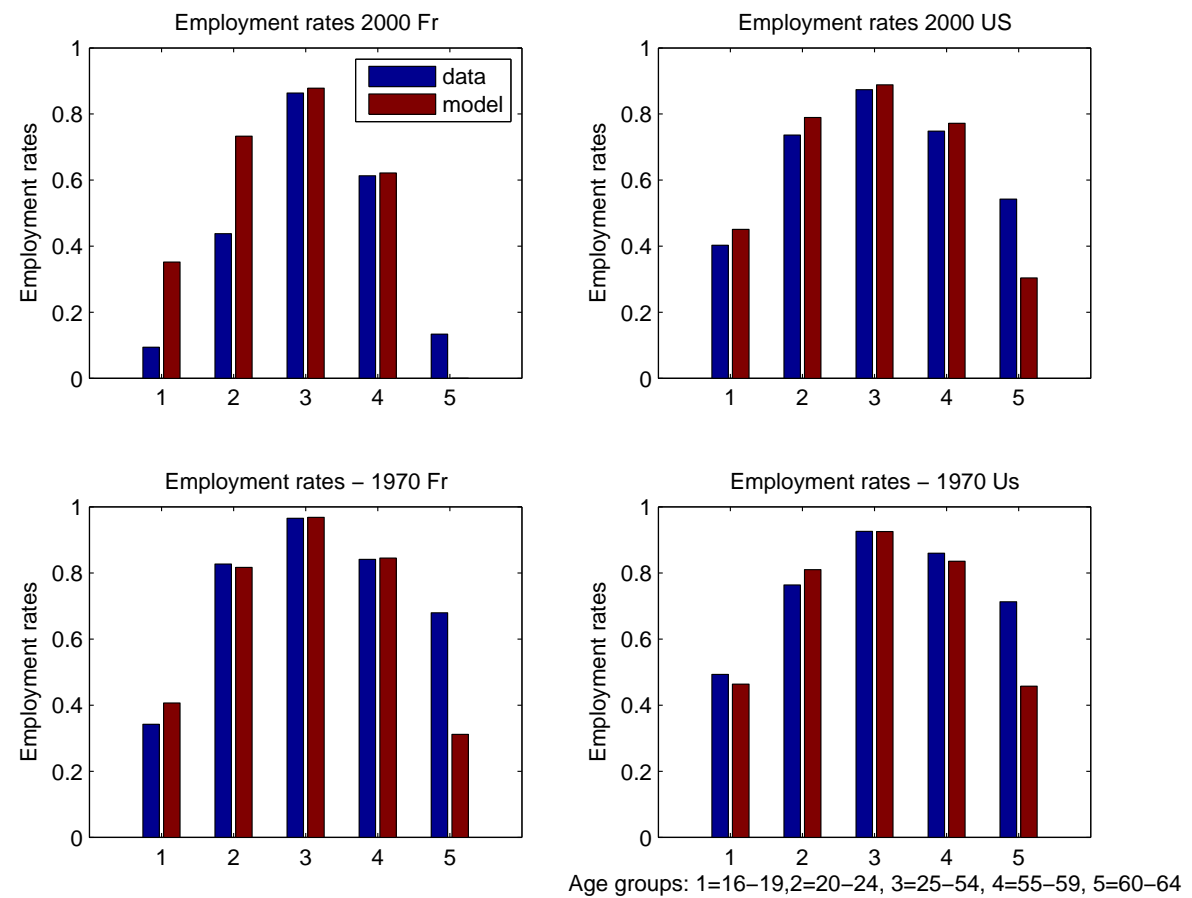

Figure 9 shows that the age-distribution of the employment rates is stable over time in the US, except for the 60-64 age group which displays a small

\footnotetext{
${ }^{8}$ Note that we recalibrate the home production parameters in order to match the employment rates of the 25-49 age-group in the US and in France.
} 
decrease over this period. On the other hand, in France the age-distribution of the employment rates is largely modified: between 1970 and 2000, we observe a large decline in the employment rates of the younger and the older workers, whereas the employment rate of the prime-age worker is stabler. For the US, the change in the retirement age allows us to explain a large part of the decline of the employment rate before this age. On the other hand, in the French economy, the observed change in the institutions allows us to explain an important part of the shift in the employment rates by age. Indeed, for the young workers, the lower level of both the unemployment benefits and the firing costs allows us to reproduce a higher employment rate at the beginning of the life cycle, whereas the increase in the retirement age increases the employment rates at the end of the life cycle. Nevertheless, our results suggest that our model is not able to account for the large decline in the employment of younger workers in France between 1970 and 2000. Again, this can be explained by the absence of a minimum wage in our theoretical framework: it was increased in France during this period and the younger workers are the population the most likely to be working at the minimum level.

\section{Conclusion}

In this paper, we adopt a life-cycle view of the transatlantic labor market performance. The facts tell us that the differences across countries are mostly located at the two extremities of the working life cycle: for instance, France experiences lower employment for both older and younger workers, whereas its employment rate for the middle-age workers is pretty similar to that of the US. Are there age-specific institutions or do labor market institutions have an age-differentiated effect? Actually, both. On the one hand, the retirement age as early as 60 in France automatically makes the employment rate of the over-60 worker lower, but also the employment rate of the 50-andover age group by shortening their horizon and then decreasing the return on search at the end of the working life. On the other hand, we show that labor market institutions that decrease labor market rotations slow the entry process into the labor market, which explains a proportion of the younger 
worker unemployment in France, without any consequences on the middleaged worker employment. 


\section{References}

[1] J. Abowd and F. Kramarz, The Cost of Hiring and Separations, Labour Economics, 10 (2003), 499-530.

[2] J. Altonji and N. Williams, Do wages rise with job seniority? A reassessment, Industrial and Labor Relations Review, 58(3), (2005), 370-397.

[3] A. Bassanini and R. Duval, Employment Patterns in OECD Countries: Reassessing the Role of Policies and Institution, WP OECD, 2006.

[4] O. Blanchard and P. Portugal, What Hides Behind an Unemployment Rate: Comparing Portuguese and U.S. Labor Markets, American Economic Review, 91(1) (2001), 187-207.

[5] A. Chéron and J.O. Hairault and F. Langot, Life-Cycle Equilibrium Unemployment, IZA working paper, 3396 (2008a).

[6] A. Chéron and J.O. Hairault and F. Langot, Age-dependent Employment Protection, IZA working paper, 3851 (2008b).

[7] P. Garibaldi and G. Violante, Firing Tax and Severance Payment in Search Economies: A Comparison, CEPR Discussion Paper, 3636 (2002).

[8] J-O. Hairault, F. Langot, and T. Sopraseuth, Distance to Retirement and Older Workers' Employment: The Case For Delaying the Retirement Age, Journal of European Economic Association, 8 (5) (2010).

[9] S. Kitao, L. Ljungqvist and T. Sargent, A Life Cycle Model of TransAtlantic Employment Experiences, mimeo, 5TH ECB/CEPR Labour Market Workshop.

[10] L. Ljungqvist and T. Sargent, European Unemployment and Turbulence Revisited in a Matching Model, Journal of the European Economic Association, 2, 2004, 456-468.

[11] L. Ljungqvist and T. Sargent, Two Questions about European Unemployment, Econometrica, 76, (2008) 1-29. 
[12] D.T. Mortensen and C. Pissarides, Job creation and job destruction in the theory of unemployment, Review of Economic Studies, 61 (1994), 397-415.

[13] D.T. Mortensen and C. Pissarides, New developments in models of search in the labor market, Handbook of Labor Economics,North-Holland:Amsterdam (1999).

[14] OECD publishing, Live longer, work longer, Ageing and Employment Policies (2006).

[15] E. Prescott, Why do Americans work so much more than Europeans?, Quarterly Review of the Federal Reserve Bank of Minneapolis, July (2004), 2-13.

[16] E. Prescott, R. Rogerson and J. Wallenius, Lifetime Aggregate Labor Supply with Endogenous Workweek Length, Review of Economic Dynamics, 12(1), (2009), 23-36.

[17] R. Rogerson, Understanding Differences in Hours Worked, Review of Economic Dynamics, 9 (2006), 365-409.

[18] R. Shimer, The cyclical behavior of equilibrium unemployment and vacancies, Ameriacan Economic Review, 95 (2005), 25-49. 